This is a preprint of an article whose final and definitive form will be published in the Australasian Journal of Philosophy; the Australasian Journal of Philosophy is available online at: http://www.tandf.co.uk/journals/.

\title{
LEIBNIZ AND THE NECESSITY OF THE BEST POSSIBLE
}

\section{WORLD}

\section{Martin Pickup}

Leibniz has long faced a challenge about the coherence of the distinction between necessary and contingent truths in his philosophy. In this paper, I propose and examine a new way to save genuine contingency within a Leibnizian framework. I conclude that it succeeds in formally solving the problem, but at unbearable cost. I present Leibniz's challenge by considering God's choice of the best possible world (Sect. 2). God necessarily exists and necessarily chooses to actualise the best possible world. The actual world therefore could not be different, for if it were different it would be a distinct and inferior world and hence would not be created. In Sect. 3 I defend Leibniz from this challenge. I argue that while it is necessary for God to choose to create the best possible world, it is not necessary for any world to be the best possible. This is because the criterion for judging perfection can itself be contingent. Different criteria will judge different worlds as the best. Thus it is necessary for God to create the best, but not necessary which is the best. Distinguishing between possible worlds in Leibniz's sense and in the modern sense allows a fuller exposition of this position. There are worries that can arise with the claim that the criterion of perfection is contingent. I consider two of the most pressing (Sect. 4). The first argues that the criterion is in God's understanding and hence is necessary; the second alleges that a contingent criterion of perfection violates Leibniz's cherished Principle of Sufficient Reason. These worries are well-grounded, and examining them reveals a deep incompatibility between this solution and Leibniz's metaphysical views. I conclude that there is a real solution available, but that it is unacceptable to Leibniz or a Leibnizian. The search for a genuine solution that is genuinely Leibnizian goes on. 


\section{Introduction}

Contingency and necessity are topics of perennial interest in the philosophy of Leibniz. Leibniz himself repeatedly discussed matters in this area. ${ }^{1}$ These topics have continued to be an area of investigation for his commentators. One consequence of the energy expended is a startling array of interpretations of Leibniz's views on necessity and contingency. There is some consistency, however, on the sort of questions of interest: Is there any space for contingent propositions in Leibniz's system? Is Leibniz a necessitarian? What is the connection between the many accounts Leibniz gives of contingency and freedom? What are the details of his preferred account? Did he change his mind on these issues, or did he have a settled position throughout his career?

These are all valuable questions, which have received close analysis in a number of places. I shall attempt to add some thoughts on merely the first of them. This means that I shall not be focussing very closely on exegesis. There are subtle and important issues about precisely what Leibniz thought, and at different stages of his career; I wish to sidestep these issues. Instead, I will be asking whether there is a plausible way for Leibniz to maintain his core principles and yet hold onto a worthwhile difference between the contingent and the necessary.

There are a number of ways to generate worries for Leibniz in this area. I will focus on one of the main lines of difficulty for Leibniz, which is the challenge to contingency from a necessary God necessarily creating the best possible world. I elaborate this problem in the next section. I will then offering a route out of the quandaries which I hope is, if not Leibniz's view, at least Leibnizian. I

\footnotetext{
${ }^{1}$ The number of documents in AG which cover the issue and cognate areas demonstrates this. (See references for abbreviations).
} 
conclude by examining some serious objections to such an escape and offer replies. Although I am focusing on only one form of the difficulty for Leibniz in maintaining the necessary/contingent distinction, I take what I say to be applicable to the other ways to challenge him over the issue.

\section{A problem for Leibniz}

Leibniz's philosophy exhibits extraordinary interconnections and dependencies, and it can be difficult to know where to start to investigate his thought on any particular issue. We shall simply focus on one strand of Leibniz's problems concerning contingency, that concerning God's creation of the world, which will show why doubts have been raised about the consistency of his views with a genuine distinction between necessity and contingency.

The thesis that gives rise to the worry is the claim that God creates the best possible world. A good starting-place to understand this notion is theological. Leibniz held that God was the creator of the world, described in 'On the Ultimate Origination of Things' as 'the ultimate and extramundane reason for things' [AG 150/G vii. 303]. He also held that God was metaphysically necessary. In the same passage he argues: 'since the ultimate ground must be in something which is of metaphysical necessity ... it follows that there must exist some one entity of metaphysical necessity.' [ibid.] In the Monadology 44 this is expressed as follows: 'reality must be grounded in something actually existent; therefore it must be grounded in the existence of the necessary being, in whom essence includes existence, that is, for whom being possible is sufficient for being actual.' [WF 273-4/G vi. 614] So, we have a metaphysically necessary creator. What is the nature of this creator? The Monadology 41 provides us with our answer: 'God is absolutely perfect' [WF 273/G vi. 613; see also Discourse 1]. Now, when it comes to the creating done by this creator, Leibniz notoriously held that this is the best possible world. He held this view because he thought both that God, being perfect, would create the best world that God could, and also that God can create any world. Let's investigate this further. 
The third paragraph of the Discourse is 'Against those who think God could have done things better', where Leibniz states: 'Nor could I ever endorse the view . . . that what God does is not of the utmost perfection, and that he could have done things much better. ${ }^{2}$ [WF 55/G iv. 428] The Monadology 53-55 reiterates this point. In that passage, Leibniz says that, 'that is the reason for the existence of the best [possible world], which God's wisdom brings him to know, his goodness brings him to choose, and his power brings him to produce.' [WF 275/G vi. 616] Elsewhere, in the 'Dialogue on Human Freedom and the Origin of Evil', he asserts: 'I believe God did create things in ultimate perfection, though it does not seem so to us considering the parts of the universe.' [AG 115/Gr 365] Thus God, who is metaphysically necessary, creates the best of the possible worlds.

If God, who is metaphysically necessary, chooses the best possible world, then how can anything be contingent? God's creation of the best possible world is because of God's immutable nature, which entails choice of the best. The actual world, then, is the best. In virtue of this, it must therefore be chosen. And how could anything be different? Possible worlds are defined by the things and events in them. So if anything were different we would have a different possible world, and so not the best, and so it wouldn't be chosen to be actual. The actual world thereby, in virtue of being the best, inherits God's metaphysical necessity as it is entailed by a metaphysical necessity.

\section{A Leibnizian reply}

We shall try to present a coherent picture that is Leibnizian but not necessitarian. In doing so, we hope to avoid the charge that Leibniz is unable to maintain a distinction between contingent and necessary truths.

\footnotetext{
${ }^{2}$ I take it that the 'much' here is for emphasis, or is stylistic. Leibniz didn't think that God could have done things even slightly better.
} 
Despite being the grandfather of possible worlds, Leibniz's understanding of necessity and possibility is not that of the $20^{\text {th }}$ and $21^{\text {st }}$ centuries. So we should begin by defining these modal notions in Leibniz's way. Leibniz analysed necessity and contingency in terms of contradiction: a truth is necessary only if its negation implies a contradiction in a finite number of steps, otherwise it is contingent. ${ }^{3}$ One (of many) places Leibniz appeals to this is in the Discourse 13 [WF 63-6/G iv. 4369]. To switch this into propositional talk, we can say that a proposition is necessarily true if its negation implies a contradiction in a finite number of steps, necessarily false if it implies a contradiction in a finite number of steps and otherwise contingent.

In our previous paragraph there is repeated use of the phrase 'in a finite number of steps'. This is key, and can be connected to Leibniz's famous doctrine that in all true propositions the predicate is contained in the subject. ${ }^{4}$ Leibniz has a notion of analysis whereby the containment of the predicate in the subject of a true proposition can be brought out, and hence a true proposition can be reduced to an identity. ${ }^{5}$ But Leibniz distinguishes between necessary truths, where this analysis is finite and completable, and contingent truths, where the analysis is infinite and incompletable. This is intimately connected to the definition described above. If the analysis of a necessary proposition will terminate in an identity, the negation of this proposition will demonstrably entail a contradiction. Because the analysis of a contingent proposition is not completable, its negation does not demonstrably entail a contradiction. Now, Adams and others take Leibniz to succeed in saving contingency on his own definition; it is not possible to demonstrate the contradiction that follows from the negation of a contingent truth. But Adams claims this is not

\footnotetext{
${ }^{3}$ Leibniz sometimes speaks of a contrary, rather than a negation. I do not take the difference to be material to the case we present for contingency.

${ }^{4}$ See, e.g., in his letter to Arnauld in July 1686: 'in all true affirmative propositions, necessary or contingent, universal or singular, the notion of the predicate is always in some way included in that of the subject - the predicate is in the subject - or I do not know what truth is.' [WF 111-2/G ii. 56] See also the Discourse 8. ${ }^{5}$ Leibniz appeals to mathematical analogies to explain his notion of analysis (see, e.g., 'On Contingency' [AG 28-30/Gr 302-6]), and there is continued debate as to how best to understand this; see Adams [1994: sect. I], Hawthorne and Cover [2000 and Rodriguez-Pereyra and Lodge [2011] for some discussions.
} 
enough for real contingency. ${ }^{6}$ For even if we can't derive the contradiction in a finite number of steps, it still seems to be there! Although the analysis of the subject and predicate does not finitely produce an identity, the predicate is still contained in the subject. The negation of any proposition is false in virtue merely of the concepts involved, and seems impossible. If the negation of a truth is impossible, it's very hard to accede to Leibniz's claim that it is not necessary. So it seems like Leibniz may have found an interesting difference between two classes of propositions, but that this difference is not between necessity and real contingency. I want to see if we can do better on Leibniz's behalf and save both contingency in Leibniz's sense and in the fuller sense that corresponds to 'real' contingency. In order to do so, we need to make clear what is meant by 'real' contingency.

I take this latter sense of contingency to be one without the qualification of 'in a finite number of steps' and hence simply: a truth is necessary if its negation implies a contradiction and contingent otherwise. ${ }^{7}$ This can be parsed using modern possible worlds: a proposition is necessary if it is true in all possible worlds and contingent if it is true in at least one possible world but not in all. We shall see later that when Leibniz speaks of possible worlds he doesn't mean the same as Lewis, Stalnaker or Kripke. But we can use the modern notion to capture what we want to save in Leibniz's system, i.e. real contingency.

With this in mind, we can begin our defence of contingency in Leibniz's philosophy by approaching the issue of God's creation of the best possible world. One way to maintain real contingency would be to deny that God's choice of the best world is necessary (perhaps by grounding this choice in God's freedom). In this way no contradiction would follow from the negation of a contingent proposition. But, as we have suggested above, given that God's decision to create the best world is determined by God's nature it seems that God's choice is necessary. God is

\footnotetext{
${ }^{6}$ See Adams [1994: 28-30] for a survey of those who prosecute Leibniz with this charge, for Adams's defence of Leibniz on his own account of contingency and for Adams's rejection of this account.

${ }^{7}$ Adams mentions another candidate for necessity: conceptual truth. The degree of overlap between this and the sense of contingency proposed in the text cannot be investigated here.
} 
by nature perfectly good, so it's part of God's nature to always choose the best. Furthermore, God's nature is itself necessary. So it seems God must choose the best. God therefore necessarily chooses the best world. However, and this is the key point, it is not thereby necessary that the actual world is chosen. For contingency can enter elsewhere. I contend that it is contingent which is the best possible world.

This possibility is recognised in Adams, but in other places is overlooked. ${ }^{8}$ It is easy to overlook. For it is indeed necessary that the best possible world is actual qua best possible world. But it might not be necessary for world $w$ to be actual, which contingently is the best possible. Or, to use a familiar distinction, the proposition, 'the best possible world necessarily exists' is true when 'best possible world' is read de dicto but not when it is read de re.

To bring this out, compare our situation with a similar scenario. An eccentric benefactor invites ten people to a dinner party. The dinner party is peculiar, however, because the benefactor commits to giving a million pounds to the person who is her favourite at the end of the dinner. She enters a binding contract to this effect. Suppose it is Ann who is the favourite and given the money; it is (legally) necessary that Ann is given the money qua favourite but it is by no means (legally) necessary that Ann is the one given the money because it is not necessary (legally or otherwise) that she is the favourite.

So, there is conceptual space for a view where God necessarily creates the best world, but that world is not necessary because it is not necessarily the best. But why might it be that it is contingent that some world $w$ is the best possible world? To investigate this, we'll need to step back and consider the properties of worlds that make them good. This question has received a thorough

\footnotetext{
${ }^{8}$ E.g. Griffin [2012: 59-60], where he moves from 'it's necessary that the best of all possible worlds is actual' to 'whatever happens in the actual world is necessary.' The former is only established by the previous premises on a de dicto reading of 'best possible world', while the latter only follows from a de re reading.
} 
analysis by Blumenfeld. ${ }^{9}$ Leibniz says a great deal about this, and it is not obviously consistent. Put simply, worlds are ordered by perfection. What is less clear is (i) what perfection is in general and (ii) what Leibniz understands to be the criterion for judging the perfection of worlds in particular. ${ }^{10}$ I will briefly discuss these in turn.

Perfection plays a central role in Leibniz's metaphysics. This can be seen from the fact that discussion of perfection opens the Discourse, whose first line is: 'The most widely accepted and the most meaningful notion of God which we have is fairly well expressed in these terms, that God is an absolutely perfect being'. Leibniz goes on: 'there are several completely different perfections in nature ... God possesses all of them together and ... each of them belongs to him in the highest degree. ${ }^{11}$ [WF 54/G iv 427] Thus there are distinct perfections, which can be had by degrees. Debate continues as to how to understand Leibniz's views on what perfections are, though it is clear that God's properties furnish us with examples: power, knowledge and the like. One natural thought is that they are a particular class of properties, though this really just postpones the question: which class of properties are they? I do not want to enter this interpretive debate here. Whatever perfections are, this is a distinct question to what perfection is. As a simple means of expressing the contention of the paper, I shall take perfection to be a second-order property which supervenes on the properties that are perfections, i.e. perfection is a further property that something has in virtue of having some other, more primitive properties. The perfection of some entity $A$ is therefore parasitic on the other properties that $A$ has. As an example, the perfection of some particular piano will be a function of some of the more basic properties that the piano has. Presumably, these more basic properties would include timbre, aesthetic form, durability and so on. What we are interested in is the nature of the parasitic relationship between $A^{\prime}$ s perfection and $A^{\prime}$ s properties with regard to the perfection of a certain sort of entity: worlds. This is precisely the next issue to consider.

\footnotetext{
${ }^{9}$ See Blumenfeld [1995].

${ }^{10}$ Thanks to an anonymous reviewer for highlighting the need to talk about the first of these.

${ }^{11}$ This, along with the coherence of God's concept, is the basis for Leibniz's ontological argument.
} 
What does Leibniz take to be the criterion for perfection for worlds? Or: what properties are those upon which the degree of the perfection of a world supervenes? At the level of worlds, the prime candidate for a criterion of perfection is a combination of simplicity in laws and richness in phenomena. ${ }^{12}$ There are places, however, where Leibniz suggests other criteria (such as sheer volume of existence or maximising perspectives on the world). ${ }^{13}$ One way to bring out the interpretive issue is to consider the Monadology 41 and 58, which, in the space of a few pages, seem to present competing accounts of perfection. The former tells us that perfection is simply the total amount of positive reality (i.e. existence), while the latter equates the greatest amount of perfection with the greatest variety and order possible. Blumenfeld's account renders these consistent, but at any rate we can see the prima facie challenge. But what I want to say can be stated in a way independent of the precise criterion of perfection; it concerns the status of the criterion of perfection rather than its contents. So for the sake of exposition, $I^{\prime} l l$ assume that perfection is determined by a balanced combination of simplicity of laws and richness of phenomena.

We can generate a weak ordering according to these properties and their relative weighting, so that each possible world is ranked but there can be ties. ${ }^{14}$ But thus far, this doesn't seem to help. Because worlds are fully determined by their constituent parts, and it is these constituent parts that give a world's simplicity in laws, richness in phenomena and its balance between the two, worlds essentially have the position they do in the ranking of perfection according to this criterion. Thus the best world seems essentially the best world and therefore necessarily created.

Here, though, is my central hypothesis: the criterion for perfection is not necessarily the criterion for perfection. Simplicity in laws and richness in phenomena (or whatever you take to be Leibniz's considered criterion) are not necessarily the properties that make a world good. A

\footnotetext{
12 See, e.g., Discourse 5, Principles of Nature and Grace 10.

${ }^{13}$ See Blumenfeld's second section for evidence of these and others.

14 Though there may be equally good worlds, Leibniz will insist that the best world must be unique, for otherwise God wouldn't create a world as there would be no reason to choose one rather than the other. C.f. Theodicy 196. If we have a strong ordering, the uniqueness of the best world falls out as a consequence.
} 
proposition is necessary if its negation entails a contradiction. But there is no obvious contradiction is supposing that, for example, sheer volume of existence is what ranks the quality of worlds (or elegance, or only simplicity and so on). Worlds certainly can be ranked according to such criteria, and there is nothing that appears to prevent these being rankings of perfection. In other words, it's hard to see why the properties these criteria track could not be the properties upon which perfection supervenes. The alternatives seem perfectly internally consistent, and they do not conflict with any mathematical or metaphysical truths. Thus the negation of the proposition that perfection is ordered by the criterion it is in fact ordered by doesn't lead to contradiction and is not necessary. It is thereby really contingent.

At first blush, this seems consistent with what Leibniz says. In discussing the Euthythro dilemma in the Discourse 2, he explicitly takes goodness to be independent of God's will; he takes this horn of the dilemma. What is good is not good because God chooses it, but God chooses it because it is good (in fact, to be precise, the best). He says, 'I also find the claim by some other philosophers completely strange when they say that ... the rules of goodness, justice, and perfection, are only the effects of God's will' [WF 55/G iv. 428]. In the Theodicy 193 Leibniz is at pains to assert that goodness doesn't rely on God's choice, but rather the dependence goes the other way: 'I have shown that the Will of God is not independent of the rules of Wisdom' [H 247/G vi. 231$]^{15}$. God's choices are governed by God's knowledge of what is best rather than what is best being determined by God's choice.

The impression that Leibniz would have been content with the contingency of which world is the best will be discussed further below. At this stage, though, we can take the criterion of perfection to be a primitive; separate from but equally foundational as mathematics and logic. Being distinct from mathematics and logic, which are governed by the law of non-contradiction, alternative

${ }^{15}$ See also Theodicy 175-183, which gives arguments for the claim that what is good does not depend on God's volitions. 
criteria of perfection do not entail a contradiction and hence the actual criterion is not necessary. The actual world is the best possible, but it is not necessary that the actual world is the best. God chooses governed by what it best, and as this is not necessary, neither is God's choice. In this way, we can provide a contingent root for God's choice of world, a contingence which thereby infects things in the world.

We should spell out a little more clearly what the proposal is. The claim is that the negation of the actual criterion of perfection does not entail a contradiction, thus the actual criterion of perfection is contingent. Because we want to talk of the possibility of different criteria that govern which world God chooses to create, we need to introduce some terminology for precision. When Leibniz talks of possible worlds he is talking about the ways the universe could be, among which God selects the one which is the best. These 'possible worlds' in Leibniz's sense we shall call possible universes. The modern sense of 'possible worlds' is broader than this, so that a possible world would contain within it the criterion of perfection that God uses to choose between possible universes, and indeed God. ${ }^{16}$ We reserve the term 'possible world' for such an entity. Possible worlds, in this sense, are second-order possibilities; possibilities detailing which possible universe will be chosen given which possible criterion. This is not the sense of possible world found in Leibniz. Having made this distinction, we can be more precise about our suggestion.

First let's make some stipulations. These stipulations are not essential to the project, but will aid exposition. The first stipulation is that the range of possible universes from which God chooses is the same in each possible world. ${ }^{17}$ The second stipulation is that God, a necessary being, exists in

\footnotetext{
${ }^{16}$ Plantinga's ontological argument, for example, relies on God's necessary existence being understood as existence in all possible worlds.

${ }^{17}$ I.e. possible universes are the same in all possible worlds. This is related to the principle $\mathrm{S} 5$ in modal logic, which all worlds are accessible from all others and hence modal properties are constant across all possible worlds.
} 
each possible world and evaluates the goodness of possible universes in each possible world. ${ }^{18} \mathrm{~A}$ third stipulation is that the possible worlds vary with respect to the criteria of perfection that govern God's choice of which universe to create. With this in place, we can consider the modality of specific propositions.

A true proposition $p$ will only be contingent under the following circumstances: (i) there is possible world $w$ in which God selects as best a nonactual universe $u$ and (ii) $p$ is false in $u$. Or, equivalently, (i) there is a possible criterion of perfection $C$ according to which a nonactual universe $u$ is best and (ii) $p$ is false in $u .{ }^{19}$ We might well ask whether every possible universe among which God chooses has a corresponding possible world in which it is actualised. In other words, we can ask whether every possible universe is such that there is a criterion of perfection that uniquely identifies it as best. One the one hand, it seems parsimonious to treat all universes the same in this way ${ }^{20}$ On the other, though, it may seem unpalatable that a chaotic universe which doesn't contain many things could be selected as best. In order to distinguish between universes as candidates to be best in a world, we could need some restriction on criteria of perfection.

Such a restriction would have an interesting consequence. Some universes which are among those from which God chooses will not be chosen in any possible world. In such a case we might say that these universes are possible in themselves but not strictly possible. ${ }^{21}$ We would then have two species of possible universe: those that are merely possible in themselves and those that are strictly

\footnotetext{
${ }^{18}$ This stipulation will need some clarification, which follows in the discussion below of challenges to the proposal (Sect. 4.1).

${ }^{19} \mathrm{An}$ anonymous reviewer has pointed out that, in addition to the 'proposition by proposition' approach to establishing which are genuinely contingent, we could use the alternative criteria of perfection to render sets of propositions contingent. For instance, a criteria of perfection that prizes economy above all else would make all propositions concerning finite existence contingent.

${ }^{20}$ Furthermore, given certain views of properties and perfection, the correspondence between worlds and universes will be trivial (e.g. if the degree of any property can be a sole criterion for perfection and any world is uniquely maximal in at least one property).

${ }^{21}$ Leibniz himself talks about things being possible 'in themselves', but it is dubious that he meant precisely this distinction.
} 
possible. The strictly possible universes will be the ones that ground real contingency. ${ }^{22}$ Propositions would be likewise categorised; those whose negations are true in strictly possible universe would be really contingent, those whose negations are only true in universes merely possible in themselves would also be merely contingent in themselves. Those whose negations are true in no possible universes we can call strongly necessary. Leibniz would thereby have a three-fold division of propositions into those that are strongly necessary, those that are contingent in themselves and those that are really contingent. ${ }^{23}$

Whether we want to accept that every possible universe has a criterion according to which it is the best or not, there seems further work to do to examine possible criteria for perfection and consider the consequences this has on which propositions are necessary and contingent. At the very least, though, the sketch provided suggests that a core of Leibniz's system permits genuine contingency and can avoid the challenge from God's creation of the best. But rather than filling out this sketch, I will raise and discuss a serious challenge to our forgoing argument. The challenge is whether Leibniz can hold that the criterion of perfection is contingent. If the challenge cannot be overcome, then further elaboration would not be worthwhile.

\section{Objections to the view}

Our picture relies on the claim that the criterion of perfection is contingent. There are at least two reasons to doubt this, which we shall consider in turn. The first is that the criterion of perfection appears to reside in God's understanding and that, given God's necessary existence, it thereby

\footnotetext{
${ }^{22}$ It would be interesting to investigate whether the universes merely possible 'in themselves' were those such that contained no really contingent truths but did contain truths contingent in Leibniz's sense, i.e. in the sense that no contradiction could be derived from their negation in a finite number of steps.

${ }^{23}$ The parsimonious view where every possible universe has a corresponding possible world in which it is the best can therefore be restated in these terms as the claim that the set of propositions contingent in themselves is empty; every proposition is really contingent or strongly necessary.
} 
appears necessary. ${ }^{24}$ The second is that the contingency of the criterion of perfection would violate one of Leibniz's core principles, that of Sufficient Reason.

\subsection{The necessity of God's understanding}

We noted in the previous section that the evidence suggests that Leibniz saw the criterion of perfection as independent of God's will. The criterion of perfection in fact governs God's will by informing God's choice between alternatives. But nevertheless the criterion of perfection is not completely independent of God. In the same passage in the Discourse 2 Leibniz says that the rule of goodness depends on God's understanding, like 'the eternal truths of metaphysics and of geometry' [WF 55/G vi. 428]. In the Theodicy 189, too, Leibniz states: 'there must be a reason accounting for the preference for order and regularity, and this reason can only be found in understanding. Moreover these very truths can have no existence without an understanding to take cognizance of them; for they would not exist if there were no divine understanding wherein they are realised, so to speak.' [H 246/G vi. 229] The comparison with the truths of metaphysics and geometry is not promising, as the truths of metaphysics and geometry are necessary.

The worry can be drawn out when we consider an issue raised in a different context by Wilson [1978/9]. ${ }^{25}$ Leibniz's view of complete concepts of individual substances has been dubbed by Mondadori [1973] as 'super-essentialist'; all of a substance's properties are essential to it. God is an individual substance. ${ }^{26}$ Hence all of God's properties are essential. But God is also a necessarily existent being, so exists in all possible worlds. Our problem is that if God's properties include the contents of God's understanding then the criterion of perfection, which resides in God's understanding, is also present in all possible worlds and is thereby necessary.

\footnotetext{
${ }^{24}$ My thanks to Gonzalo Rodriguez-Pereyra for raising and discussing this issue with me.

${ }^{25}$ I am grateful to Paul Lodge for pointing out this paper to me.

${ }^{26}$ See the Discourse 35 [WF 87-8/G iv. 460-1] and Principles of Nature and Grace 9 [WF 262/G vi. 602-3]
} 
How can we block this argument? At first sight there seem at least three options. ${ }^{27}$ In the first place we could claim that God's properties do not include the contents of the divine understanding, secondly we could claim that not all God's properties are essential and thirdly we could claim that God's necessary existence doesn't require that God exist in all possible worlds.

Of course these replies will not want to assert that everything in God's understanding is contingent. We must be able to distinguish within God's understanding between the necessary truths of geometry, mathematics and metaphysics on the one hand and the criterion of perfection (and possibly of beauty, justice etc.) on the other. This corresponds to Leibniz's distinction between metaphysical and moral necessities. Thus the aim is to assert that the criterion of perfection is in God's understanding like the truths of metaphysics and geometry but that it is crucially not like the truths of metaphysics and geometry in a different way, i.e. by not being necessary. We should therefore turn to these three suggestions to see if they can achieve this requisite distinction.

It might seem hard to assess the plausibility of the first option. Omniscience is certainly one of God's properties, but whether or not the contents of God's omniscient understanding are divine properties is unclear. It seems open for the advocate of my view to simply deny this, but it is admittedly hard to motivate such a denial. It would require an investigation of both properties and the divine understanding in Leibniz's thought that is impossible here.

The second option mentioned above would make God a unique individual substance that differs from all other substances by not having all properties essentially. If not all God's properties

\footnotetext{
${ }^{27}$ The second and third of these are also discussed in Wilson [1979]. One line of defence that seems initially promising is raised in the sentence preceding the above quotation from Theodicy 189. It states, "In the region of the eternal veracities are found all the possibles, and consequently all the regular as well as the irregular." If all possible criteria of perfection are found in God's understanding then no particular one seems necessary. This faces the problem, though, that God's understanding must be responsive to which criteria is actual in each world, and so must somehow differ between worlds if the criteria do. Thus this reply merely postpones the issue.
} 
are essential then God's properties can differ between possible worlds, and hence God's

understanding can differ between possible worlds. Some of the contents of God's understanding, viz. the criterion of perfection, can therefore be contingent. This move seems to be somewhat ad hoc. On the other hand, however, God is certainly unique in a number of ways (for instance by being the only necessarily existing being), and this extra uniqueness might not be a significant cost. ${ }^{28}$

We can already see a reason, though, why there might be serious concerns for the viability of either of these first two approaches. Leibniz took all possible and necessary truths to be grounded in the necessary existence of God (c.f. Monadology 43-44). ${ }^{29}$ The current proposals both seem to undermine this claim. As regards the first, consider the truth the following proposition: 'criterion $C$ is the criterion of perfection.' The criterion of perfection varies from world to world while God does not; how then can the truth of 'criterion $C$ is the criterion of perfection' depend on God? God is invariant across worlds, but the truth or falsity of this proposition isn't; it is true in some worlds but not others. Hence it cannot depend on God for its truth (or falsity).

As regards the second, consider again the claim that all possible and necessary truths rely on God's necessary existence. One natural way to understand Leibniz's thought is that the complete inventory of what is true at each world follows from God's nature. If this is the case, how can God's nature vary from world to world? One attempted reply might use our previous distinction between possible worlds and possible universes, suggesting that God's nature merely determines what is true at each universe within a world, and that it not the ground of what is true in each possible world.

\footnotetext{
${ }^{28}$ As Paisley Livingston has pointed out, further complications ensue when we recognise that God is also perfect. If perfection for worlds and perfection for God are interconnected, what the criterion for perfection is for worlds will have consequences for God's perfection and hence nature. Thus it seems that God's nature must be different in different worlds if the criterion of perfection varies. This pushes us towards this second response. As noted on $\mathrm{p} 8$, however, I do not want to enter the debate about what perfection is, in general, for Leibniz.

${ }^{29}$ Thanks to an anonymous referee for raising this point, which is also appealed to below.
} 
While this does save the argument, it does so at the cost of rejecting Leibniz's claim that all truths depend on God. This seems unacceptable. ${ }^{30}$

So we should look to the last option, which would require us to finesse what is meant by necessary existence such that something can necessarily exist but not exist in all possible worlds. One prime candidate for just this sort of understanding of necessity is provided by Lewisian counterpart theory. According to this view, individuals in the actual world have counterparts in other possible worlds rather than existing in more than one world. These counterparts ground the modal claims in our world. So, for instance, my assertion that Jones could have dropped the eggs on the way home is made true (if it is true) by the fact that one of Jones's counterparts in another possible world did indeed drop the eggs on the way home. ${ }^{31}$ Thus God could necessarily exist by having counterparts in all possible worlds, not by existing in all possible worlds. The counterpart relation has been thoroughly investigated and discussed, and this is not the place to rehearse these debates. But if we can avail ourselves of the counterpart relation for God, then it could be the case that, strictly speaking, God only exists in this possible world, but has appropriate relations to beings in all other possible worlds such that it is true that God necessarily exists. Furthermore, what it would mean to say that God's understanding, and hence the criterion of perfection, is contingent is that in another possible world a counterpart of God has different understanding (containing different a criterion of perfection). Thus we would have saved the contingence of the criterion of perfection despite their location in God's understanding.

This seems to me the most promising approach. But there are a couple of warning flags which indicate that fully working-out this picture will prove troublesome. The first is that Lewis's

${ }^{30} \mathrm{~A}$ further way to press the worry for the second proposal is as follows: if all possible and necessary truths are grounded in God's necessary existence then how can could God having different properties in different possible worlds give rise to different real possibilities? The fact that this is the actual world is a fact that must rely on God's necessary existence, and hence the other possible worlds (and other properties of God) aren't really possible. This sort of objection is also discussed below, pp20-22.

${ }^{31}$ The picture is more complicated than this initial account suggests. In particular, it involves judging between possible worlds as to their relative similarity in order to prioritise those that are 'closer' to one another. See the final chapter of Lewis [1986]. 
own counterpart relation is part of his wider project, and the wider project included the thesis of modal realism. This is the claim that (all) non-actual possible worlds exist. In fact, I think that Leibniz could have accepted this. He could have claimed that every possible world is real, and in each possible world God creates the best possible universe according to the relevant criterion of perfection. But I also think it is pretty clear that Leibniz didn't think this. One primary reason is that this would entail a number of Gods, each of whom satisfied the ontological argument for the perfections that are pertinent in that world..$^{32}$ These Gods, distinct but related by the counterpart relation, seem to fly in the face of Leibniz's most fundamental metaphysical and theological commitments.

So, in order to offer this escape to Leibniz, we need a form of counterpart theory that takes non-actual worlds as non-existent. And we can then legitimately query whether a counterpart relation holding between God and some non-actual entity belonging to a non-existent possible world is sufficient for real contingency..$^{33}$ Again, we have to defer here to debates over this question in the modality literature, but suffice it to say that the Leibnizian who takes this view of God's necessary existence will have to convince us of the capacity of the counterpart account to give us the full sense of contingency we desire.

Any of the three approaches outlined would allow us to maintain that the criterion of perfection is indeed in God's understanding but remains contingent. However, each of them faces serious challenges. The third suggestion, that God is strictly confined to a world but has counterpart

\footnotetext{
${ }^{32}$ This connects to Wilson's criticism of any use of the counterpart relation in the Leibnizian context. Her criticism is that, if God is not numerically identical across possible worlds, a number of different 'Gods' would each satisfy the ontological argument and hence all exist and create their corresponding universes. Thus Wilson thinks that counterpart theory entails modal realism for Leibniz. I do not. I disagree because an ontological argument already relies on a notion of perfection. So we can consistently claim that only one world exists, hence only one criteria of perfection is actual, and hence that only the God corresponding to this criterion of perfection exists (and provably exists from the ontological argument).

${ }^{33}$ Thanks to an anonymous reviewer for this observation
} 
relations to entities in other worlds that ground the truth of the proposition that God exists necessarily, seemed the most promising. But even that view has significant further work to do. So the Leibnizian thesis that the criterion of perfection depends on God's understanding causes as-yetunresolved issues for the proposal I have outlined.

\subsection{Principle of Sufficient Reason}

The second worry about the proposed account of contingency comes from Leibniz's Principle of Sufficient Reason (PSR), which is itself one of the ways to present a difficulty for contingence in his system. The PSR is stated in the Monadology 32 as follows: '[the principle] of sufficient reason, in virtue of which we hold that no fact could ever be true or existent, no statement correct, unless there were a sufficient reason why it was thus and not otherwise' [WF 272/G vi. 612]. This principle asserts that there are no brute facts, and Leibniz describes it as one of the two great principles of our reasoning (the other being that of non-contradiction).

The picture we have offered seems in tension with the PSR as it seems to introduce arbitrariness into Leibniz's philosophy. We can ask: what is the sufficient reason for some criterion of perfection to hold rather than others? If we cannot answer this question, or at least find some plausible account of why the PSR fails in this case, then the cost of the solution appears disastrously high. One way to phrase this criticism is in terms of possible worlds, in the sense introduced above. If there are at least two possible worlds with different criteria for God's choice of which universe to create then why is one possible world actual and the others not? ${ }^{34}$

\footnotetext{
${ }^{34}$ As Paisley Livingston has indicated to me, much will turn here on Leibniz's understanding of creation. A view such as Mercer's [2002] where creation is emanation might further undermine the proposed account of the distinction between necessary and contingent truths. But, as there are other insuperable problems for the account, we can grant the most favourable interpretation of creation, namely creation as choice between determinate possible universes.
} 
We shall try to respond to this criticism, and to do so we need to look more closely at the PSR and its ground. It is intimately tied to God's choice of the best world. In fact, the PSR is sometimes even called the principle of the best. ${ }^{35}$ The reason the PSR holds within a universe is that the omniscient God has necessarily chosen the best possible universe and that every event in that world is constitutive of it. The actual universe is the best possible, hence for every actual event $e$ the universe would be worse if $e$ didn't happen. The precise way in which the universe would be worse might not be transparent to us. But God is rational, so must have a reason for choosing $e$ over the alternatives. This is why there must be a sufficient reason for any actual event to obtain.

The Leibnizian who wants to accept our proposal above, therefore, may offer the following defence of its consistency with the PSR: in our description of the basis for the PSR we have already brought in evaluative language. For any actual event $e$ the sufficient reason for it obtaining is that otherwise things would be worse. God's acting in accordance with the criterion for perfection in a possible world is the reason that the PSR holds. If, per impossibile, God were to refrain from acting according to the criterion of perfection then there would be no justification for supposing that the PSR applies. So in fact it transpires that the reason that the PSR itself is true is the fact that God is, by nature, perfect and acts in accordance with the criterion of perfection. But then the PSR is logically downstream from the criterion of perfection. As we have argued above, if the criterion of perfection were different then the universe chosen by God would be different, and the reasons for events to obtain would be different. Therefore the sufficient reasons for things depends on which criteria of perfection is actual.

To put it another way: for some actual event $e$ there is a reason why it is so and not otherwise. This reason has to do with the richness of phenomena and simplicity in laws that is the actual criterion of perfection. But in a different possible world, with a different criterion of perfection, $e$ might not have this sufficient reason. Sufficient reasons are thus indexed to criteria of

\footnotetext{
${ }^{35}$ See the Stanford Encyclopedia article on the PSR for one example of this.
} 
perfection or, equivalently, to possible worlds. The PSR therefore applies to events within possible universes, but not to all events within possible worlds. This would give us a principled reason for rejecting the question above: what is the sufficient reason for one criterion of perfection to hold rather than another? There is no answer to this question because the obtaining of criterion of perfection is an example of something that takes place in worlds not universes, and hence does not fall under the domain of the PSR. We can say that there is no answer to this question without rejecting the PSR per se if it is understood as applying within universes. It seems we can therefore hold on to both the PSR and the account of contingency presented above.

Unfortunately, however, there are serious doubts about the coherence of such a position. In the first place, there are textual concerns about the faithfulness of this interpretation of the ground of the PSR. The PSR seems to govern God's choice of which universe to actualise; in the Monadology 53 Leibniz states that 'since there are an infinite number of possible universes in the ideas of God, but only one can exist, there must be a sufficient reason for the choice God makes, which determines him to choose one of them rather than another.' [WF 275/G vi. 616]. This straightforwardly contradicts the assertion above that the PSR holds in universes but not in worlds. ${ }^{36}$ Now, textual matters are seldom conclusive; Leibniz may not have been consistent on this point and debate can continue as to the viability of the interpretation proposed above. But there is a more decisive theoretical problem here too, one that does show that Leibniz could not have accepted the account offered to him.

Even if an arbitrary criterion of perfection is not against the letter of the PSR, it is against the spirit. For we then have a fundamental and vitally important brute fact underlying the whole edifice of Leibniz's philosophical system. The brute fact is this: that criterion $C$ is the criterion of perfection. If this were not sufficiently contrary to Leibniz's project, closer reflection leads to more startling consequences. If the fact that $C$ is the actual criterion of perfection is brute, then it cannot be

\footnotetext{
${ }^{36}$ Thanks to an anonymous reviewer for pointing to this text.
} 
explained. It also, therefore, cannot depend on anything. In particular, consider God's role in the creation of the universe. God, understood as existing within a possible world, chooses between possible universes to create on the basis of their degrees of perfection. Their degrees of perfection are governed by a criterion over which God has no control, and which is part of the structure of the possible world. In different possible worlds, different criteria of perfection obtain and hence God makes different choices. But which possible world obtains (and hence which criterion of perfection obtains) is a matter of brute chance.

This is clearly unacceptable for Leibniz, as it makes something independent of God. ${ }^{37}$ In fact, here we can see a parallel to the worries with the location of the criterion of perfection in God's understanding considered in the previous section. How can the criterion of perfection depend on God if God has no choice among possible worlds? Similarly, how can they reside in God's understanding if God only exists within worlds and they are world-level features?

I think there is a diagnosis of these fundamental worries. It is connected to the distinction between possible worlds and possible universes that undergirds the proposed account of contingency. In the presented picture, God exists within possible worlds, not outside them. While this is one way to understand God's position (and is, for instance, crucial to modern modal ontological arguments), it cannot be Leibniz's. It is not enough for God to be extramundane in the sense of being outside possible universes, God must be outside possible worlds too. If not, then God has no say over which world is actual. This flies in the face of God's sovereignty. It also places a brute fact as the centre-piece of the philosophical system. And if God is extramundane in the sense of being outside possible worlds as well as outside possible universes, the distinction between possible worlds and possible universes collapses, and the proposed account of contingency fails. For this reason, then, I suggest that the attempt to save a genuine distinction between necessary and

\footnotetext{
${ }^{37}$ One reviewer, who flagged this difficulty, also indicated the possibility that Leibniz could assert some rigid, higher-order necessity about criteria of choice. But I agree that this very rigidity would fatally undermine contingency, and so is not a viable escape.
} 
contingent truths is unsuccessful. It is not Leibniz's view, and it is not even a viable Leibnizian view: a Leibnizian who denied God's sovereignty wouldn't be worthy of the name.

In this section we have considered two objections against the account of contingency presented in section 2 and have attempted to defend the account against them. The objection both rely on a deeper worry about the role of God in our proposal. This worry is a good one, and the cost of avoiding it is overwhelming for a Leibnizian. The proposal, while internally consistent, is not consistent with core elements of Leibniz's metaphysics. Unfortunately, therefore, we have not discovered a viable distinction between necessity and contingency in a Leibnizian system.

\section{Conclusion}

This paper presents a longstanding problem in Leibniz's philosophy and offers a solution to it. The problem is how to reconcile Leibniz's clear desire for genuine contingency with his view of the nature of God and of God's creative activity. By looking at God's choice of universe, and in particular at the criterion of perfection that governs such a choice, I have suggested one way that contingency can be saved. If it is contingent what the criterion of perfection is then it is also contingent which world is the best. It is therefore contingent which world is chosen by God, i.e. which world is actual. Distinguishing between possible worlds in the contemporary sense and possible worlds in Leibniz's sense (which I dub 'possible universes') allows us to give an outline of the picture.

Although this view seems to get Leibniz his desired contingency, it does so only at a supreme cost. Not only is the criterion of perfection brutally arbitrary, flying against the spirit of the PSR, the picture also requires that which criterion hold is independent of God. God does not choose which world (and hence which criterion) exists. This is unpalatable to Leibniz and the Leibnizian. 
Thus, while I have presented one internally consistent way for Leibniz to maintain a real distinction between contingent and necessary truths, this account is not consistent with his wider views. The search for a Leibnizian solution to this issue goes on. ${ }^{38}$

New College, Oxford

\section{References}

Primary Sources with Abbreviations

(AG) Philosophical Essays. Translated and edited by Roger Ariew and Dan Garber. Indianapolis: Hackett, 1989.

(G) Die philosophischen Schriften. 7 vols. Edited by C. I. Gerhardt. Berlin, 1875-90. Reprint, Hildesheim: Georg Olms, 1965.

(Gr) Textes inédits d'après les manuscrits de la Bibliothèque provinciale de Hanovre. 2 vols. Edited by Gaston Grua. Paris: Presses Universitaires de France, 1948.

(H) Theodicy: Essays on the Goodness of God, the Freedom on Man and the Origin of Evil. Translated by E. M. Huggard. La Salle, IL: Open Court, 1985.

(WF) Philosophical Texts. Edited and translated by R.S. Woolhouse and Richard Francks. Oxford: Oxford University Press, 1998.

Secondary Sources

${ }^{38}$ I am very grateful to Gonzalo Rodriguez-Pereyra, Paul Lodge, Paisley Livingston and two anonymous reviewers for this journal for their comments and suggestions, which have substantially improved this paper. 
Adams, Robert Merrihew 1994. Leibniz: Determinist, Theist, Idealist, Oxford: Oxford University Press.

Blumenfeld, David 1995. Perfection and Happiness in the Best Possible World, in Nicholas Jolly (ed.) Cambridge Companion to Leibniz: 353-82.

Griffin, Michael 2012. Leibniz, God and Necessity, Cambridge: Cambridge University Press.

Hawthorne, John and Jan Cover 2000. Infinite Analysis and the Problem of the Lucky Proof, Studia Leibnitiana, 32/2: 151-65.

Lewis, David 1986. On the Plurality of Worlds, Oxford: Blackwell Publishers

Mercer, Christia 2002. Leibniz's Metaphysics: Its Origins and Development, Cambridge: Cambridge University Press

Mondadori, Fabrizio 1973. Reference, Essentialism, and Modality in Leibniz's Metaphysics, Studia Leibnitiana, 5/1: 74-101.

Rodriguez-Pereyra, Gonzalo and Paul Lodge, 2011. Infinite Analysis, Lucky Proof, and Infinite Proof in Leibniz, Archiv für Geschichte der Philosophie, 93/2: 222-36.

Wilson, Margaret D. 1978/9. Possible Gods, Review of Metaphysics, 32/4: 717-33. 